\title{
Retraction Note: Effects of chronic treatment with the eNOS stimulator Impaza on penis length and sexual behaviors in rats with a high baseline of sexual activity
}

\author{
X. Chu • E. S. Zhavbert · J. L. Dugina • I. A. Kheyfets - S. A. Sergeeva • O. I. Epstein · A. Ågmo
}

Published online: 23 June 2020

(c) The Author(s) 2020

Retraction to: International Journal of Impotence Research https://doi.org/10.1038/ijir.2013.12

The editor has retracted this article because there are concerns about the scientific validity of the study. Specifically, the reagent is diluted beyond the point to which any active molecules are expected to be present and there is no molecular analysis to support the presence of molecules at these dilutions. These concerns have caused the editor to lose faith in the reliability of the findings.

All authors disagree with this retraction. 